\title{
La participación e implicación de las familias en un centro privado de Granada
}

Recibido: 9 de julio de 2018 / Revisado: 19 de octubre de 2018

Aceptado: 27 de noviembre de 2018 / Publicado: 19 de diciembre de 2018

VACAS-QUINTANA, ANA ISABEL

GARCÍA-GARNICA, MARINA

Departamento de Métodos de Investigación y Diagnóstico en Educación Universidad de Granada, España

mgarnica@ugr.es

DOI: $10.24310 /$ IJNE1.1.2018.4954 FALTA

\section{RESUMEN}

Son muchos los expertos y las investigaciones que evidencian que la implicación de las familias en los centros educativos tiene una influencia positiva sobre la calidad de la educación, aumentando el rendimiento de los alumnos y su motivación, y reduciendo la tasa de abandono. Es por ello que se presenta una investigación ${ }^{1}$ cuyo objetivo general es conocer el grado de participación e implicación de las familias de los alumnos de primer ciclo en la propia escuela y en la educación de sus hijos, así como las vías que emplean para ello, en un centro privado de la provincia de Granada.

Para alcanzar este objetivo se va a emplear una metodología de encuesta, siendo la entrevista semiestructurada en profundidad la técnica escogida para la recogida de la información y los participantes los cuatro tutores del primer ciclo de Educación Primaria del centro en cuestión. En cuanto al análisis de la información, se ha segui-

\section{ABSTRACT}

Family participation and involvement in a private school in Granada

There are many experts and studies that show that the family involvement in schools has a positive influence on the quality of education, increasing student performance and their motivation, and reducing the dropout rate. The aim of this research is to determine the degree of participation and involvement of the families of students in the school and in the education of their children, as well as the ways they use for this, in a private school in Granada.

In this research, a survey methodology was used. The data collection technique was the semi-structured interview and the participants were the four form teachers of the first cycle of Primary Education of this school. Regarding the data analysis, a qualitative pro-

1 La investigación presentada forma parte del Trabajo Fin de Grado titulado "La participación e implicación de las familias de los alumnos de primer ciclo de un centro privado de Granada en la escuela y en la educación de sus hijos" elaborado por la alumna Ana Isabel Vacas-Quintana (curso 2017-2018) con la colaboración y supervisión de la Dra. Marina García-Garnica. 
do un proceso propiamente cualitativo, usando el software informático Nudist Vivo como medio de apoyo.

Los resultados recogidos muestran que las familias de los alumnos están, por lo general, implicadas en el centro educativo a través de los diferentes órganos de participación y tomando parte activa en las actividades que este organiza. Igualmente, conocen la línea de trabajo de la escuela y la apoyan. En lo relativo a la educación de sus hijos, también están bastante involucrados, acuden a las tutorías cuando se les cita, se reúnen con el tutor y con otros profesionales del centro cuando lo requieren, manteniéndose informados del progreso académico y personal de sus hijos. No obstante, aunque esta es la línea predominante, también hay familias que están menos implicadas o que no lo están tanto como quisieran, en estos casos la razón primordial son las ocupaciones laborales.

Palabras Clave: Educación Primaria, Implicación Familiar, Participación Familiar, Mejora Educativa. cess has been carried out, using the Nudist Vivo software as a support.

The results show that families are involved in the school through the different bodies of participation and taking an active part in the activities that are organized. Likewise, they know the line of work of the school and support it. Regarding the education of their children, they are also quite involved, attending the tutorials when they are scheduled, meeting with the form teacher and other professionals of the school when they need it, keeping informed of the academic and personal progress of their children. However, although this is the predominant line, there are also families that are less involved or that are not as involved as they would like, in these cases the primary reason is lack of time doe to their jobs.

Keywords: Primary Education, Family Involvement, Family Participation, Educational Improvement.

\section{Introducción}

Es muy difícil llegar a una definición de familia en occidente, puesto que ha habido numerosos cambios durante la última década, los más relevantes asociados al género, que han transformado el concepto de familia tradicional, dando lugar a una gran variedad de modelos (Valdivia, 2008).

Como manifiesta Muñoz (2005), esta evolución se ha ido produciendo por los distintos cambios sociales e históricos que han tenido lugar en nuestra sociedad y que han afectado, en mayor y en menor medida, a la propia concepción de familia y de infancia, y a la perspectiva que se tiene de la función que juega la familia en el progreso de sus hijos. Como señala Maese (2009), algunas de las principales causas que han provocado modificaciones en las circunstancias familiares son:

1. La gran incorporación de la mujer al mundo laboral.

2. El nacimiento de hijos fuera del matrimonio.

3. El incremento del número de familias monoparentales, donde padre o madre cubren el rol de ambos progenitores a la vez. 
En definitiva, la concepción de la familia engloba matices jurídicos, biológicos y sociales, varía de una cultura a otra, y aunque se encuentre dentro de la misma civilización pueden hallarse subculturas, como la rural o la urbana (Valdivia, 2008).

Siguiendo a este mismo autor, actualmente podemos diferenciar entre varios tipos de familia: familia tradicional, familia troncal y troncal extendida, familia nuclear reducida, familia y hogares monoparentales, uniones de hecho, parejas homosexuales, familias reconstituidas, polinucleares o mosaico y nuevos modelos que están surgiendo hoy en día, como pueden ser por ejemplo, familias por inseminación de mujeres de 65 años de edad que quieren tener un hijo.

En cualquier caso, con independencia de la concepción que tengamos de la familia y del modelo o tipo de familia ante el que nos encontremos, debemos tener claro el gran papel que juega en la educación de sus hijos. Estas tienen una labor muy importante en el desarrollo personal y social de los mismos, especialmente en sus primeros años de vida (Muñoz, 2005).

La familia es un factor elemental en el rendimiento y el éxito escolar de los alumnos (Garreta, 2015). Distintos autores (Bolívar, 2006; Colás \& Contreras, 2013; García, Martín \& Sampé, 2012) afirman que cuando se establece un buen clima de trabajo cooperativo entre la familia y la escuela la calidad educativa del centro presenta un gran ascenso. Esto se debe a que los alumnos aumentan su rendimiento académico y su motivación, reduciéndose la tasa de abandono y aumentado los índices de graduación.

Pero al mismo tiempo que la familia ha sufrido como institución una importante modificación, los centros educativos también han vivido sus propios cambios; destacando fundamentalmente, la diversificación funcional que ha experimentado el profesor, pasando de ser transmisor de conocimientos a dinamizador de aprendizajes, gestor de conflictos, educador de valores, facilitador de las TIC, formador de hábitos de salud y de estudio, gestor del ocio saludable, agente socializador, dinamizador de las relaciones de grupo, mediador en la integración de culturas, etc.

Como afirman García, Gomáriz, Hernández \& Parra (2010), la situación escolar ha cambiado tanto que el profesorado se ve expuesto a una gran presión psicológica, enfrentándose a la desmotivación y falta de respeto de los alumnos, la desconfianza, pasividad y desautorización de los padres o la interminable adaptación a continuas reformas educativas.

Asimismo, la escuela como centro de vida, demanda hoy más que nunca de la colaboración de la familia, puesto que el profesorado por sí sólo es insuficiente para dar respuesta a las diversas necesidades educativas que pudieran llegar a demandar los alumnos (García et al., 2010).

Como señala Jurado (2009), la familia y la escuela deben trabajar cooperativamente para favorecer el desarrollo total del alumnado en los diferentes ámbitos de su personalidad (motor, social, cognitivo o afecti- 
vo), ambos se encuentran íntimamente relacionados y, por ello deben trabajar conjuntamente. Además, la familia y la escuela son contextos del desarrollo infantil diferenciados, que se complementan adecuadamente.

Las diversas características de la relación familia-escuela pueden llegar a tener una gran repercusión en el desarrollo personal de los niños y niñas (Jiménez, Lorence \& Menéndez, 2008). Es importante saber que, familia, escuela y comunidad son tres elementos que deberán compenetrarse de una forma adecuada para que surja un buen efecto de esta combinación. La cooperación entre estos tres agentes educativos es fundamental para mejorar la educación (Bolívar, 2006).

En efecto, la implicación de las familias en la educación de sus hijos y, más concretamente, en la escuela afecta positivamente en el proceso de aprendizaje de los mismos. Sin embargo, a pesar de ello, distintas investigaciones recalcan la escasa participación de las familias en la escuela. San Fabián (1996), por ejemplo, pone de manifiesto que dicha implicación va siendo más difícil conforme va ascendiendo el nivel educativo del alumnado.

Por otro lado, como afirma Jurado (2009), tenemos que ser conscientes de que existen numerosas dificultades a la hora de que los padres participen en el centro educativo, siendo estas principalmente de tres tipos: personales, institucionales e individuales.

Es un dato de interés conocer que la participación de la familia en la escuela en nuestro país es un derecho de corta tradición, que tiene su origen en la Constitución de 1978 y se desarrolla en la Ley Orgánica del Derecho a la Educación (LODE) del año 1985, quedando recogido en su artículo 29, el cual reconoce la participación de los padres y madres de los alumnos en los Consejos Escolares, y es el marco en que se apoya el art. 118 de la Ley de Educación (LOE) del año 2006. Además, en el artículo 2 de la Ley General de Ordenación del Sistema Educativo (LOGSE) del año 1990, se reconoce también la obligación de implicar a los padres de los alumnos para alcanzar los distintos objetivos educativos (Aguilar \& Leiva, 2012).

Por otro lado, debemos saber que la participación e implicación de los padres y madres de los alumnos en los centros de enseñanza es un indicador fundamental para conocer la Calidad de los Sistemas Educativos, por eso se le otorga a este tema una gran importancia en la vertiente político-legislativa y científica.

Asimismo, el Programa de Formación de Padres de la Asociación Europea de Padres de Alumnos (EPA) es un claro ejemplo de cómo mejorar la calidad de la relación entre el profesorado y la familia a través del diálogo y la cooperación de ambos agentes. La función de estos cursos no es otra que la de enseñar el importante papel que juegan los padres en la educación de sus hijos (Colás \& Contreras, 2013).

Pero, ¿qué canales existen para la comunicación familia-escuela? Garreta (2015) elabora un listado en el que incluye entre otros: las reuniones al comienzo del curso académico, las tutorías, las circulares y 
notas, la agenda escolar, el panel de anuncios, la web y blog del centro, y las comunicaciones informales (por vía telefónica, por ejemplo).

Siguiendo a García et al., (2010), de entre las diferentes vías para establecer comunicación con el profesorado, los padres usan sobre todo las reuniones de grupo y las entrevistas. Estas son las consideradas más útiles, debido a que se abordan cuestiones más concretas y que tienen como protagonistas a los hijos. Por otra parte, también se utiliza la agenda escolar o el horario de tutoría como herramientas de comunicación, y aunque son menos usadas también se piensa que son útiles.

Cabe decir que las TIC han supuesto un gran avance a la hora de facilitar la comunicación entre familias-escuela, un ejemplo de esta comunicación pueden ser los blogs, ya que en varios centros las asociaciones de padres y madres los han abierto para comunicarse con el resto de las familias y transmitir informaciones o eventos de interés que van a tener lugar tanto dentro como fuera del centro educativo, como por ejemplo excursiones o sesiones de teatro (Aguilar \& Leiva, 2012).

Estamos inmersos en la era de las nuevas tecnologías, y esto puede ser una gran herramienta para utilizarla satisfactoriamente para la mejora de la relación familia-escuela, un ejemplo sería el uso del WhatsApp. Es interesante comentar que, el uso de los grupos de WhatsApp por parte de las familias del alumnado del centro no es tan nocivo como se cree, pero tampoco es tan provechoso como lo pueden defender los grupos sociales más jóvenes y más informados sobre este tema. Ya sabemos que WhatsApp es una red social y por lo tanto, tendrá tanto aspectos positivos como negativos, dependiendo del enfoque que se le dé a su uso y de la regulación que exista con respecto a los contenidos publicados (Cascales, Gomariz \& Martínez, 2017).

Acerca de la necesidad de que se lleve a cabo un aumento de la colaboración de las familias en el proceso educativo de los alumnos, se puede decir que en base a distintas evidencias científicas, los centros educativos deberían crear espacios y diversas actividades para la participación de las familias de forma educativa, evaluativa y decisoria (García et al., 2012). Según la investigación de Gil (1994), los padres del alumnado están más motivados por los aspectos académicos que por otros y, también es de interés mencionar que, conforme a este estudio, se aprecia que se producen un mayor número de visitas de las familias en los centros privados que en los públicos.

En definitiva, la idea de participación familiar en lo que se refiere a competencia se puede entender como una capacidad que puede ser entrenada, fomentada, desarrollada y ejercitada, que va un paso más allá de las características propias que tienen las familias. Desde este punto de vista, el papel del tutor es de gran importancia, debido a que esta figura es la que permite que se establezcan buenas relaciones entre escuela y familia (Castro, Expósito, Lizasoain, López \& Navarro, 2015). 
Como se ha analizado, son muchos los expertos y las investigaciones que evidencian que la implicación de las familias en los centros educativos tiene una influencia positiva sobre la calidad de la educación, aumentando el rendimiento de los alumnos y su motivación, y reduciendo la tasa de abandono. Es por ello que se presenta una investigación cuyo objetivo general es conocer el grado de participación e implicación de las familias de los alumnos de primer ciclo de un centro privado en la propia escuela y en la educación de sus hijos, así como las vías que emplean para ello. Este objetivo se concreta en los siguientes:

1. Conocer el contexto en el que se enmarca la escuela.

2. Identificar las características principales de las familias de los alumnos de primer ciclo.

3. Averiguar cómo es la relación familia-tutor y cuáles son las principales vías de comunicación.

4. Conocer si las familias mantienen comunicación con otros profesionales del centro.

5. Conocer el grado de implicación de las familias en la escuela y el modo en el que lo hacen.

6. Identificar el nivel de implicación de las familias en la educación de sus hijos.

7. Averiguar las principales causas que llevan a las familias a no implicarse en el centro y en la educación de sus hijos.

\section{Metodología}

En la presente investigación se va a emplear una metodología de encuesta, que consiste en conseguir diversos datos a partir de cuestiones realizadas a componentes de una población o de una muestra, empleando como técnica el cuestionario o la entrevista (Buendía \& Colás, 1992).

Para el proceso de recogida de la información, la herramienta seleccionada es la entrevista, que como afirman Bernardo y Calderero (2000), se podría definir como un diálogo que tiene una intención y está conducido para conseguir unos objetivos. Concretamente, y siguiendo la clasificación establecida por Meneses y Rodríguez (2011), se trata de una entrevista semiestructurada, en profundidad, no directiva e individual.

En relación al procedimiento de construcción del guion de la entrevista, los pasos que se han seguido han sido los siguientes (Meneses \& Rodríguez, 2011):

1. Establecer el objeto de estudio y los objetivos de la investigación.

2. Realizar una revisión de la literatura.

3. Reconocer los tópicos y las temáticas de interés.

4. Elaborar un primer guion de preguntas. 
5. Revisar las preguntas, organizarlas por categorías, otorgarles una secuencia lógica y añadir, eliminar o reunificar algunas de ellas.

6. Mejorar de la redacción y el formato de las preguntas que componen la entrevista.

7. Revisión de las preguntas por parte de un experto para asegurar su relevancia, pertinencia y claridad.

Tabla 1. Cuestiones incluidas en la entrevista.

\begin{tabular}{|c|c|c|}
\hline $\begin{array}{c}\text { EJE DE } \\
\text { INDAGACIÓN }\end{array}$ & PIES & $\begin{array}{c}\text { ASPECTOS CONCRETOS QUE SE ESPERAN } \\
\text { ENCONTRAR EN LA RESPUESTA }\end{array}$ \\
\hline $\begin{array}{l}\text { Contextualización } \\
\text { del centro }\end{array}$ & $\begin{array}{l}\text { Vamos a hablar, en primer lu- } \\
\text { gar, de la escuela en la que tra- } \\
\text { baja, ¿cómo es el contexto en } \\
\text { que se enmarca? }\end{array}$ & $\begin{array}{l}\text { - ¿Cuáles son las principales características de } \\
\text { la zona? } \\
\text { - ¿Cuáles son las características del alumnado? } \\
\text { ¿Qué nivel social, económico y cultural tienen } \\
\text { las familias? } \\
\quad \text { ¿Cuáles piensa que son los puntos fuertes de } \\
\text { la escuela en la que imparte docencia? }\end{array}$ \\
\hline $\begin{array}{l}\text { Características de } \\
\text { las familias }\end{array}$ & $\begin{array}{l}\text { ¿Cuáles son las principales ca- } \\
\text { racterísticas de las familias de } \\
\text { sus alumnos a nivel social, eco- } \\
\text { nómico y cultural? }\end{array}$ & $\begin{array}{l}\text { - ¿Cuál es la procedencia de las familias de su } \\
\text { alumnado? } \\
\text { - ¿Qué nivel educativo tienen dichas familias? } \\
\text { ¿En general, en qué trabajan los padres de sus } \\
\text { alumnos? } \\
\text { ¿Cuál es la edad media de las familias? }\end{array}$ \\
\hline $\begin{array}{l}\text { Comunicación } \\
\text { familia-tutor }\end{array}$ & $\begin{array}{l}\text { Hábleme de su relación con } \\
\text { las familias de sus alumnos. } \\
\text { ¿Mantiene una comunicación } \\
\text { fluida con ellas? ¿Qué vías uti- } \\
\text { liza para ello? ¿Cuál es la acti- } \\
\text { tud de las familias y cuáles son } \\
\text { las principales dificultades que } \\
\text { encuentran para mantener una } \\
\text { comunicación fluida con usted? }\end{array}$ & $\begin{array}{l}\text { - ¿Mantiene reuniones con las familias median- } \\
\text { - } \quad \text { ¿Con qué frecuencia? } \\
\text { - ¿Cuáles son los principales temas tratados? } \\
\text { - ¿Cuál es la actitud, grado de asistencia y par- } \\
\text { ticipación de las familias? } \\
\text { - ¿Quiénes son los más implicados? ¿Padre, } \\
\text { madre o ambos? } \\
\text { - } \quad \text { las no están implicados, ¿cuáles cree que son } \\
\text { ¿Qué otros canales se utilizan para la comuni- } \\
\text { cación tutor-familias? } \\
\text { ¿Cuál es su grado de implicación y accesibi- } \\
\text { lidad? }\end{array}$ \\
\hline
\end{tabular}




\begin{tabular}{|c|c|c|}
\hline $\begin{array}{c}\text { Comunicación } \\
\text { familias-otros } \\
\text { profesionales del } \\
\text { centro }\end{array}$ & $\begin{array}{l}\text { Además de con usted, ¿las fa- } \\
\text { milias mantienen comunica- } \\
\text { ción con otros profesionales del } \\
\text { centro? }\end{array}$ & $\begin{array}{l}\text { - ¿Con quiénes? } \\
\text { - ¿Por qué razones? } \\
\text { - Si no es así, ¿cuáles cree que son las princi- } \\
\text { pales causas? }\end{array}$ \\
\hline $\begin{array}{l}\text { Implicación de } \\
\text { la familia en el } \\
\text { centro }\end{array}$ & $\begin{array}{l}\text { ¿Cuál cree que es el grado de } \\
\text { implicación de las familias de } \\
\text { sus alumnos en el centro? ¿De } \\
\text { qué modo participan y en qué } \\
\text { actividades y órganos están im- } \\
\text { plicados? ¿Cuáles son las prin- } \\
\text { cipales causas de la no partici- } \\
\text { pación? }\end{array}$ & $\begin{array}{l}\text { ¿Participan en actividades formativas (escuela } \\
\text { de padres, charlas...)? } \\
\text { - ¿Participan en comisiones de trabajo llevadas } \\
\text { a cabo en el centro (de ciclo, de convivencia, } \\
\text { para recaudar fondos, de infraestructuras...)? } \\
\text { - ¿Participan en actividades de apoyo al centro } \\
\text { (talleres, charlas profesionales, salidas, excur- } \\
\text { siones, exposiciones, apoyo a actividades...)? } \\
\text { ¿Forman parte de órganos de participación } \\
\text { como el AMPA o el Consejo Escolar? ¿Parti- } \\
\text { cipan en las actividades que organizan? } \\
\text { ¿Cuáles son en su opinión las principales cau- } \\
\text { sas que justifican que las familias no partici- } \\
\text { pen y se impliquen a nivel de centro? }\end{array}$ \\
\hline $\begin{array}{c}\text { Implicación de } \\
\text { las familias en la } \\
\text { educación de sus } \\
\text { hijos }\end{array}$ & $\begin{array}{l}\text { ¿Considera que las familias es- } \\
\text { tán implicadas en la educación } \\
\text { de sus hijos? ¿De qué forma lo } \\
\text { hacen? ¿Cuáles son las causas } \\
\text { que pueden explicar la ausencia } \\
\text { de implicación? }\end{array}$ & $\begin{array}{l}\text { - ¿Comparten las familias los objetivos educa- } \\
\text { tivos del centro? } \\
\text { - } \quad \text { ¿Hablan con sus hijos sobre lo que hacen en } \\
\text { la escuela? } \\
\text { - } \quad \text { ¿Se mantienen informados de cómo van en el } \\
\text { colegio? } \\
\text { - ¿Se mantienen informados de las dificultades } \\
\text { - } \quad \text { ¿Coe pueden presentar? } \\
\text { de estudio? } \\
\text { ¿Las familias ayudan, supervisan u orientan a } \\
\text { sus hijos en la realización de sus tareas? } \\
\text { ¿Qué principales dificultades pueden llegar a } \\
\text { encontrar los padres para no implicarse en la } \\
\text { educación de sus hijos? }\end{array}$ \\
\hline
\end{tabular}

A su vez, los participantes que nos aportan la información necesaria para realizar el estudio son los cuatro maestros-tutores del primer ciclo de primaria del centro en cuestión:

- Docente 1: es la tutora del curso $1^{\circ} \mathrm{A}$ de primaria. Tiene 53 años y lleva más de 30 dedicados a la docencia, la mayoría de ellos en este centro. Durante 20 años consecutivos ha sido tutora del primer curso de primaria y durante 6 coordinadora de ciclo. 
- Docente 2: es el tutor del curso $1^{\circ} \mathrm{B}$ de primaria. A sus 56 años, lleva en este centro trabajando 35. Ha pasado por todos los ciclos de primaria, y lleva 24 años ejerciendo docencia en el primer ciclo. Además, actualmente es el coordinador del mismo y ha desempeñado este puesto durante cinco años.

- Docente 3: es el tutor del curso $2^{\circ} \mathrm{A}$ de primaria. Tiene 45 años y lleva trabajando 17 en este centro. Cuenta con 20 años de experiencia docente, y además ha trabajado en otros dos centros docentes privados del mismo perfil. Ha sido tres años coordinador de ciclo y actualmente es coordinador bilingüe.

- Docente 4: es la tutora del curso $2^{\circ} \mathrm{B}$ de primaria. A sus 34 años, lleva 6 años dedicados a la docencia y este es su cuarto año consecutivo trabajando en este centro. Actualmente, es la coordinadora de la escuela de idiomas que tiene el colegio, puesto que desempeña por cuarto año.

Tabla 2. Datos descriptivos de los entrevistados.

\begin{tabular}{|c|c|c|c|c|c|c|c|}
\hline Participantes & Sexo & Edad & $\begin{array}{c}\text { Años de expe- } \\
\text { riencia docente }\end{array}$ & $\begin{array}{c}\text { Años en } \\
\text { este centro }\end{array}$ & $\begin{array}{c}\text { Tipo de } \\
\text { centro }\end{array}$ & Curso & Ciclo \\
\hline Docente 1 & Mujer & 53 & Más de 30 & 30 & Privado & $1^{\circ} \mathrm{A}$ & Primero \\
\hline Docente 2 & Hombre & 56 & Más de 30 & 35 & Privado & $1^{\circ} \mathrm{B}$ & Primero \\
\hline Docente 3 & Hombre & 45 & 20 & 17 & Privado & $2^{\circ} \mathrm{A}$ & Primero \\
\hline Docente 4 & Mujer & 34 & 6 & 4 & Privado & $2^{\circ} \mathrm{B}$ & Primero \\
\hline
\end{tabular}

Para el desarrollo de la entrevista, en un primer lugar, se ha contactado con los tutores y se les ha informado del propósito de la investigación y el procedimiento a seguir, invitándolos a participar en ella. Por otro lado, una vez han accedido a colaborar, se ha fijado una fecha, hora y lugar para proceder a realizar las entrevistas, siempre respetando la disponibilidad de los participantes, por lo que se han llevado a cabo en el centro en las en las horas de libre disposición. Por último, cuando se ha producido el primer encuentro, se les ha vuelto a recordar la finalidad de la entrevista y el protocolo a seguir en el tratamiento de la información y se ha tratado de crear un clima que favorezca la recogida de los datos.

En cuanto al análisis de la información, se ha seguido un proceso propiamente cualitativo. Para comenzar, se han transcrito las entrevistas en un nivel literal (Gibbs, 2012) y se ha llevado a cabo una revisión minuciosa de las mismas para evitar los posibles errores. A continuación, se les ha facilitado la transcripción a los entrevistados para que den su visto bueno. Después, se ha realizado la categorización 
o codificación de la información, y por último, se ha efectuado un análisis horizontal de los datos obtenidos, tomando como punto de partida el sistema de categorías elaborado (Tabla 3). Para todo el proceso se ha empleado el software informático Nudist Vivo (versión 11).

Tabla 3. Dimensiones y categorías extraídas de las entrevistas.

\begin{tabular}{|c|c|}
\hline Dimensiones & Categorías \\
\hline Contexto del centro & $\begin{array}{ll}\text { - } & \text { Características zona } \\
\text { - } & \text { Características alumnado } \\
\text { - } & \text { Características familias } \\
\text { - } & \text { Fortalezas del centro }\end{array}$ \\
\hline Características de las familias & $\begin{array}{l}\text { - } \\
\text { - } \quad \text { Nivel educativo } \\
\text { - } \quad \text { Trabajo } \\
\text { - } \quad \text { Edad }\end{array}$ \\
\hline Comunicación familia-tutor & $\begin{array}{ll}\text { - } & \text { Tutoría } \\
\text { - } & \text { Frecuencia tutorías } \\
\text { - } & \text { Grado de asistencia y participación familias en tutorías } \\
\text { - } & \text { Miembro de la familia más implicado en tutorías } \\
\text { - } & \text { Causas de la no implicación } \\
\text { - } & \text { Otros canales de comunicación } \\
\text { - } & \text { Grado de implicación y accesibilidad del docente }\end{array}$ \\
\hline $\begin{array}{l}\text { Comunicación familias-otros profesio- } \\
\text { nales del centro }\end{array}$ & $\begin{array}{ll}\text { - } & \text { Relación con otros profesionales } \\
\text { - } & \text { Profesionales implicados } \\
\text { - } & \text { Razones } \\
\text { - } & \text { Causas de la no comunicación }\end{array}$ \\
\hline Implicación de la familia en el centro & 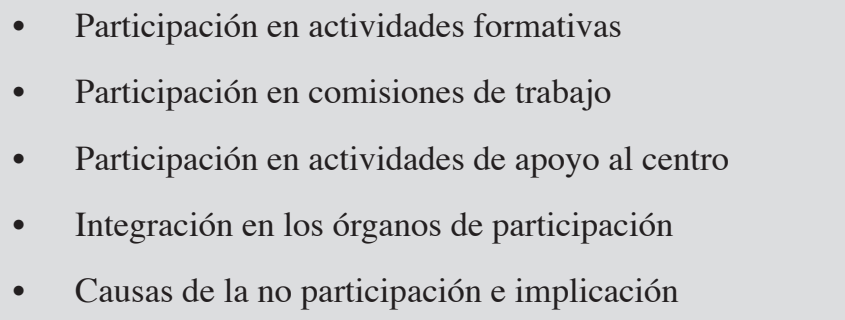 \\
\hline
\end{tabular}




\begin{tabular}{|c|c|}
\hline $\begin{array}{l}\text { Implicación de las familias en la educa- } \\
\text { ción de sus hijos }\end{array}$ & $\begin{array}{l}\text { - } \text { Objetivos centro compartidos } \\
\text { - } \quad \text { Conocimiento sobre lo que hace en la escuela } \\
\text { - } \quad \text { Información de su progreso académico y personal } \\
\text { - } \quad \text { Conocimiento del tiempo que dedican al estudio } \\
\text { - } \quad \text { Implicación en la realización de las tareas } \\
\text { - } \quad \text { Razones para no implicarse }\end{array}$ \\
\hline
\end{tabular}

Para asegurar la calidad de la investigación cualitativa, cuestión que no se puede eludir, se han empleado diferentes procedimientos (Gibbs, 2012). Por una parte, para garantizar la validez se ha recurrido a las comprobaciones constantes del proceso de categorización y a la fundamentación con fragmentos literales de texto que muestran con exactitud la opinión de los entrevistados. De otra parte, la fiabilidad se ha garantizado con comprobaciones constantes tanto de las transcripciones como de las codificaciones.

\section{Resultados}

A continuación, se exponen los principales hallazgos extraídos de la investigación. Estos se presentan organizados en diferentes subapartados, que tratan de dar respuesta a los distintos objetivos específicos establecidos en el trabajo.

\subsection{El contexto del centro}

Este centro en sus inicios estaba ubicado en una zona humilde, pero hoy en día ha cambiado totalmente. Se enmarca dentro del barrio llamado Cervantes, situado en el centro de la ciudad, y está adscrito al distrito Genil, siendo este enclave bastante tranquilo. Es una zona donde toda la demanda educativa está cubierta, tanto de colegios públicos como privados-concertados y guarderías.

"Porque lo que es el entorno de donde se encuentra el centro hay alumnado, pero no es suficiente y por lo tanto tienen que venir de otros sitios. Sería el boca en boca lo que nos hace ser más grandes y que vengan padres a conocernos, ya que las puertas y las clases están abiertas para todos los que nos quieran conocer." (Docente 2: 42)

En cuanto a las características del alumnado, el centro cuenta con un alumnado que viene de todas las zonas de los alrededores, pero que generalmente son alumnos buenos, con ganas de trabajar y que 
están muy cuidados por sus padres, aunque hay excepciones, pero son pocas. Las características de las familias, a nivel general, podrían ser que la mayoría son jóvenes y muy participativas en todas las actividades que organiza el colegio. Así, los alumnos cuentan con un buen ambiente familiar y esto es beneficioso para los niños en estas edades tan tempranas. El nivel social, económico y cultural que tendrían las familias del centro sería medio; sin embargo, también hay excepciones: algunas familias que tienen un nivel más bajo que el resto.

Los puntos fuertes del colegio se alinean con los propios de la pedagogía manjoniana: se intenta educar a hombres y mujeres cabales preparados para la sociedad en la que les ha tocado vivir.

"El centro ofrece una formación educativa personalizada, pretende el desarrollo integral de los alumnos, intenta formar a hombres y mujeres cabales preparados para asumir el papel que la sociedad le exige, dado este punto se basa en la pedagogía manjoniana, potencia la amistad, el compañerismo, la tolerancia, intenta formar a hombres y mujeres con profundas condiciones morales, religiosas y que sean sensible con los problemas que hoy se plantea la sociedad. Favorece también el orden, la disciplina, el trabajo, la solidaridad, la limpieza, el respeto, el sentido de responsabilidad y sobre todo uno de nuestros puntos fuertes es que nuestro centro tiene como insignia enseñar educando." (Docente 2: 36)

La pedagogía manjoniana hace que este centro sea diferente de los demás, ya que tiene bastante importancia la formación integral de la persona. "La instrucción tiene un valor muy importante, pero la educación lo tiene más incluso y por lo tanto intentamos encontrar un equilibrio entre instrucción y educación." (Docente 3: 45-46)

\subsection{Las características de las familias de los alumnos de primer ciclo}

En general, la mayoría de las familias provienen del barrio, pero también hay casos en los que viene alumnado de pueblos de los alrededores de la provincia de Granada. El nivel educativo de las mismas es bueno, tendiendo a ser medio-alto, aunque también hay casos en los que los padres no han podido finalizar sus estudios por diversas razones. En lo que se refiere al trabajo de las familias, hay un gran abanico de profesiones, tales como médicos, arquitectos, dependientas o maestros, aunque algunos incluso están en paro; y en cuanto a la edad media, esta estaría situada en torno a los 30-40 años.

\subsection{La comunicación familia-tutor}

Los tutores del centro tienen instaurado el horario de tutoría los martes de 16:30 a 17:30. En esta hora se establecen cuatro tutorías de quince minutos cada una, aunque en algunas ocasiones suelen alargarse. Por lo que se refiere a la frecuencia de las mismas, se dividen en tres trimestres; en el primero, 
todos los padres tienen que tenerla, y en el segundo y el tercero, tienen lugar si los padres o el tutor lo estiman conveniente.

Los temas tratados en tutorías son variados, aunque normalmente el principal podría ser el nivel académico del alumno. También, se habla sobre otros temas de interés tales como si el alumno va mal en una materia o si, por el contrario, va muy bien.

El grado de asistencia y participación de las familias en tutorías es bastante alto, puesto que todas se implican y acuden cuando los tutores los citan, salvo alguna excepción, aunque son minoría.

El miembro de la familia que está más implicado en tutorías, por lo general, es la madre; es decir, ella es la que lleva mayoritariamente el peso de la educación de su hijo. Sin embargo, en algunas ocasiones los padres también se implican en la misma medida, y en el caso de familias separadas ambos padres se involucran de forma equitativa.

Las principales causas de no implicación serían, por ejemplo, la separación de los progenitores, la juventud e inmadurez, la desestructuración familiar o la falta de tiempo ocasionada por el trabajo, aunque en algunas ocasiones también la falta de interés.

"Si no están implicados creo que las causas son muchas veces un poco de desinterés, también que vivimos una vida frenética y que no da tiempo y bueno el trabajo y las ocupaciones laborales no dejan mиcho tiempo a los padres para que se preocupen mucho por la educación de sus hijos en muchos casos." (Docente 3: 48-49)

Los diferentes canales de comunicación que utilizan los docentes para comunicarse con las familias son la agenda, la plataforma Alexia, el contacto directo mediante las tutorías, el correo electrónico e incluso el teléfono personal, en algunas ocasiones.

“Además, tenemos una representante de los padres, que es una de las madres y que tiene mi contacto directo y yo además de mandarle los correos siempre que mando un comunicado en Alexia (que además va con copia al correo electrónico para todos los padres), yo la aviso a ella directamente para que se lo comunique a los demás padres y así llegue correctamente la información a todos.” (Docente 3: 47)

El grado de accesibilidad y de implicación de los docentes es muy alto, ya que están a la entera disposición de las familias; es decir, a la hora de tener tutorías, ellos se adaptan por completo y no tienen ningún impedimento en hacerlo. 


\subsection{La comunicación familia-otros profesionales del centro}

En cuanto a si las familias mantienen relación con otros profesionales del centro, normalmente sí que la mantienen. Los principales profesionales que estarían implicados serían los maestros que imparten las diferentes materias, puesto que si el alumno va mal en una asignatura específica los padres pueden solicitar una reunión con el especialista para hablar sobre la dificultad que presenta y buscar conjuntamente una solución. También, pueden tener contacto con el director, con la orientadora, con la jefa de estudios, con la profesora del aula de integración o con el secretario, si así lo estiman conveniente.

Las razones serían principalmente cuestiones académicas: si el alumno va mal o presenta dificultad en alguna asignatura. Aunque, también, pueden tener contacto con el secretario por cuestiones administrativas o con la jefa de estudios para hablar sobre alguna inquietud que les surja. Por otro lado, las causas de la no comunicación serían, esencialmente, la falta de tiempo de los progenitores debido al horario laboral.

\footnotetext{
"Siempre se les escuch a a las familias, y siempre se les resuelven los problemas, a no ser que los padres también no sepan los canales que hay o los pasos que hay que seguir para resolver los problemas. Los padres muchas veces van directamente al director, y en muchas ocasiones el director se encuentra sin saber de qué va el asunto y les dice que hay unas pautas para estas ocasiones, es decir, un protocolo que se debe seguir." (Docente 2: 39)
}

\subsection{Implicación de la familia en el centro}

En lo relativo a si las familias participan en actividades formativas, en este centro hace algunos años sí que había escuela de padres, pero actualmente no ha tenido mucho éxito. Se cree que la principal causa de la disolución de este proyecto ha sido el horario que se tenía establecido para el mismo, ya que era en un horario en el que la mayoría de los padres estaban trabajando y no podían asistir. Además, se han propuesto diversas charlas interesantes para que las familias acudieran, pero al igual que con la escuela de padres no había mucha participación debido al horario en el que se realizaban.

"También se tienen charlas, no hace mucho citaron a los padres de primero e infantil para una conferencia a cargo de don Nicolás Crespo psicólogo y pedagogo de la facultad. La charla fue muy interesante y hubo bastante asistencia de padres, en comparación a otras ocasiones.” (Docente 1: 33)

En cuanto a si las familias participan en comisiones de trabajo, cabe decir que se muestran muy participativas en este aspecto. Colaboran bastante en las actividades que se desarrollan en el centro, muchas veces a través del propio AMPA, como la del día de Andrés Manjón, en la que se le da bollo con chocolate a 
todo el alumnado del centro, la fiesta de carnaval, la del otoño, la de navidad o la de fin de curso, y las salidas y excursiones, entre otras. También, se involucran mucho en las convivencias que se realizan cada año al finalizar el curso, que tienen como objetivo que los padres y madres de los alumnos compartan juntos una jornada. En todas estas actividades las familias están muy implicadas y ayudan en todo lo que pueden.

“En cuanto a si las familias participan en comisiones de trabajo llevadas a cabo en el centro, sí que participan a través de lo que es el AMPA y en las distintas actividades. Por ejemplo, tenemos jornadas de puertas de abiertas en las que los padres pueden venir, pueden conocer el colegio o proponer mejoras, ya que incluso hay un buzón de sugerencias en el que pueden opinar sobre cualquier cosa que haya en el centro, ya bien sea a nivel organizativo, de material, que vean algún tipo de peligro en el centro, cómo funciona el comedor o los profesores, pueden opinar de todo y tienen libertad absoluta para ello. Gracias a esto nos pueden aportar cosas, siempre que no sea una crítica destructiva, en este caso estamos tratando niños y tenemos que tener claro qué tipo de persona queremos formar.” (Docente 2: 41)

Asimismo, se han recogido fondos a través del AMPA y van a ayudar económicamente a la instalación de aire acondicionado en la planta de arriba del centro, que no disponía de ello.

Generalmente las familias están cada vez más implicadas en los órganos de participación, y sobre todo son los padres de los niños más pequeños los que se más se involucran, participando en todas y cada una de las actividades que se organizan.

“(...) hay una buena implicación, una colaboración cada vez más numerosa sobre todo en el órgano principal para ellos que es el AMPA, aunque también algunos están en el Consejo Escolar." (Docente 3: 49)

Aunque, de forma general, las familias están bastante involucradas e implicadas en el centro, cuando no es así, la principal causa es el horario laboral, puesto que muchas de las actividades que se organizan se solapan con dicho horario y no pueden acudir a las mismas tanto como les gustaría.

\subsection{Implicación de las familias en la educación de sus hijos}

Todas las familias comparten los objetivos del centro al que acuden sus hijos, ya que al fin y al cabo fueron ellos los que lo escogieron en base a los mismos y a su forma de trabajar.

"Yo considero, y como padre que he sido, que lo primero que tienen que hacer las familias es conocer qué colegio y qué características tiene. Es verdad que son cada vez más sensibles los padres y quieren 
conocer más cómo trabajamos, qué somos y qué hacemos. Los objetivos generales se les explican en las primeras reuniones y se les hace partícipes, conocen nuestra forma de trabajar y también nosotros somos un colegio que nos damos a conocer de boca en boca, es decir, son los padres los que nos traen alumnado al colegio." (Docente 2: 42)

La mayoría de los padres sí que habla con sus hijos sobre lo que han hecho en el colegio, porque les gusta estar informados sobre ello en todo momento. Por otro lado, las familias están debidamente informadas sobre el progreso académico y personal de sus hijos, también sobre las dificultades que puedan llegar a presentar en cualquier asignatura.

"Yo tengo alumnos que no separan las frases correctamente, entonces a esos niños con más énfasis les mando otras fichas para que hagan, hay otros alumnos que fallan en operaciones y yo les escribo a los padres un correo para que lo sepan y ellos o les compran a los niños cuadernillos o yo les mando fichas. Por ejemplo, la alumna que tengo con dislexia le hago más hincapié en la lectura." (Docente 4: 57)

Acerca de si las familias conocen cómo organizan sus hijos su tiempo de estudio, en el primer ciclo de educación primaria no se les suele mandar muchos deberes a casa, pero partiendo de esto, los niños tienen que repasar aquello en lo que tengan más dificultad como puede ser el caso de la lectura. Algunos padres no se pueden implicar mucho en esta tarea debido al trabajo, ya que llegan tarde y cansados y no supervisan si el alumno ha hecho lo que tenía que hacer.

"Por lo que se refiere a si los padres conocen como organizan sus hijos su tiempo de estudio, esto sea quizás lo más difícil y que para mí se debe de mejorar. Es una constante información la que yo tengo personalmente con mi tutoría para que las familias se impliquen en la educación de sus hijos, es decir, sus hijos trabajan aquí en clase pero hay que crearles un hábito de trabajo y el mismo se hace en las familias." (Docente 2: 42)

Con respecto a si se implican en la realización de las tareas, puede decirse que la mayoría sí que lo hace, pero que sin embargo hay algunas que no lo pueden hacer debido a la falta de tiempo que tienen por su ajetreado horario laboral.

"Las principales dificultades que pueden llegar a encontrar los padres para no implicarse en la educación de sus hijos, podrían ser que primeramente tienen que confiar en los tutores, no quiero decir que desconfien pero sí que es verdad que nosotros estamos aquí para ayudar, mejorar, para tratar que su hijo tenga una educación, que sean útiles y muchas veces los padres no están digamos no informados, sino que no saben qué hacer con sus hijos. Hay muchos padres y madres que están trabajando y lo que 
conlleva es que si están trabajando, estarán cansados o estresados y para ser padres hoy en día tienes que ser consciente de que tienes un hijo que es una gran responsabilidad y tienes que tener los objetivos claros, porque en definitiva los hijos son algo muy importante que hay que ayudar a encauzar y hay muchas cosas que mejorar." (Docente 2: 43)

\section{Discusión y resultados}

Se puede observar claramente que, en su mayoría, las familias de los alumnos de primer ciclo de este centro muestran un gran interés en lo que se refiere a la educación de sus hijos y por ello mantienen una buena comunicación con los tutores de los mismos, acuden a tutoría cuando es necesario y se comunican con ellos por diversos canales tales como Alexia o la agenda, entre otros. Precisamente García et al., (2010) señalaba la agenda como una de las principales vías de comunicación entre el profesorado y la familia. No obstante, como afirman Aguilar \& Leiva (2012), las TIC han supuesto un gran avance a la hora de facilitar esta comunicación, y las plataformas como Alexia constituyen una herramienta muy eficaz.

Tienen total conocimiento de lo que hacen sus hijos en el colegio, de su progreso académico y personal, de las posibles dificultades que pudieran presentar, y en su mayoría conocen el tiempo que le dedican al estudio, aunque al ser niños de corta edad no se les suele mandar muchos deberes, más bien que acaben lo que no han terminado en clase y sobre todo que lean un rato.

Los docentes están totalmente abiertos a todo lo que demanden las familias, contando con una gran accesibilidad para atenderles en todo momento y el miembro de la familia que estaría más implicado en la educación de su hijo serían principalmente las madres.

Normalmente, las familias mantienen comunicación, además de con los tutores, con los especialistas que imparten clase a sus hijos, aunque si lo ven necesario y oportuno pueden tener contacto con el secretario del centro, con la jefa de estudios, con el director o la orientadora.

Participan de forma activa en la práctica totalidad de las actividades que organiza el centro, prestando ayuda presencial, siempre y cuando su horario laboral se lo permita, y también económica. Asimismo, están totalmente integrados en los órganos de participación del centro, tales como el AMPA o el Consejo Escolar.

Nos encontramos, por tanto, ante una escuela en la que el nivel de implicación de las familias es medio-alto, tanto en el plano educativo, compartiendo los objetivos del centro, manteniéndose informados del progreso académico y las dificultades de sus hijos en las diferentes materias, conociendo lo que 
hacen en clase y cómo organizan su tiempo de estudio en casa y tratando de apoyarlos en el desarrollo de sus tareas, como en las diferentes actividades que se organizan a nivel de centro, tomando parte activa en el mismo a través de los órganos de participación.

No hay duda de que la escuela actual requiere más que nunca la colaboración de la familia para dar una respuesta adecuada a las múltiples demandas educativas (García et al., 2010). En el centro analizado, al menos en el primer ciclo, podemos afirmar que familia y escuela trabajan conjuntamente, en la misma dirección, sabiendo la importante repercusión que tiene esta relación en el desarrollo pleno del alumno (Jiménez, Lorence \& Menéndez, 2008; Jurado, 2009), siendo elemental para mejorar la calidad de la educación (Bolivar, 2006; Garreta, 2015).

Evidentemente, hay algunas familias que no participan en el mismo grado, en muchas ocasiones debido a la carga laboral. Y es que como afirma Jurado (2009), hay que ser conscientes de que las familias encuentran dificultades personales, institucionales e individuales a la hora de participar en el centro educativo.

\section{Limitaciones del estudio y propuestas de mejora}

Hay que señalar que en la realización de la investigación se han encontrado algunas dificultades y limitaciones:

1. Por impedimento de la dirección del centro, no se ha podido involucrar a las familias en la investigación ni tampoco al conjunto de los docentes. Esta limitación ha obligado a descartar la metodología cuantitativa y los beneficios derivados de la misma (la generalización de los resultados a nivel de centro). En este sentido, no se ha podido administrar el cuestionario que se había seleccionado para ello. En su lugar, y al poder trabajar solo con los tutores de primer ciclo (cuatro en total), se ha considerado que lo más apropiado era hacer uso de entrevistas semiestructuras en profundidad, que permitieran conocer a fondo lo que ocurre con respecto a la implicación de las familias en este ciclo educativo.

2. Quizás, la principal limitación de este trabajo, como se acaba de comentar, es que al no trabajar con una muestra representativa los resultados obtenidos no se han podido generalizar al conjunto del centro educativo. Sin embargo, asumida esta premisa, se ha optado por desechar este objetivo y centrar todo el trabajo en conocer en profundidad el caso en cuestión: la implicación de las familias del alumnado de primer ciclo.

3. En este sentido, tratando de salvar las limitaciones encontradas, las posibles líneas futuras de investigación podrían ser las siguientes: 
4. Combinar en la investigación técnicas de recogida de información cuantitativas y cualitativas (cuestionarios y entrevistas), que permitan un conocimiento más profundo y complementario de la realidad estudiada.

5. Realizar la entrevista a un mayor número de profesores para así conocer más puntos de vista.

6. Recoger información de otros agentes de la comunidad educativa, tales como las familias y los alumnos de los niveles superiores, pudiendo contrastar la información ofrecida por los docentes.

7. Ampliar la investigación al conjunto del centro, para obtener una visión global de lo que ocurre en el mismo en relación a la participación de las familias.

\section{Referencias}

Aguilar, M. C., \& Leiva, J. J. (2012). La participación de las familias en las escuelas TIC: análisis y reflexiones educativas. Pixel-Bit. Revista de Medios y Educación, (40), 7-19. Recuperado de: http://www.redalyc.org/pdf/368/36823229001.pdf

Bernardo, J., \& Calderero, J. F. (2000). Aprendo a investigar en educación. Madrid: RIALP, S. A.

Buendía, L., \& Colás, M. P. (1992). Investigación educativa. Sevilla: Alfar S.A.

Bolívar, A. (2006). Familia y escuela: dos mundos llamados a trabajar en común. Revista de Educación, (339), 119-146. Recuperado de: https://www.forofamilia.org/documentos/ FAMILIA\%20-\%20Familia\%20y\%20escuela.\%20Dos\%20mundos \%201lamados\%20 a\%20trabajar\%20en\%20comun.pdf

Cascales, A., Gomariz, M. A., \& Martínez, I. (2017). Grupos de WhatsApp en familias de Educación Infantil y Primaria. Revista Latinoamericana de Tecnología Educativa, 16(2), 239-255. Recuperado de: https://dialnet.unirioja.es/servlet/articulo?codigo=6244799

Castro, M., Expósito, E., López, E., Lizasoain, L., \& Navarro, E. (2015). Acciones y actitudes diferenciales de los tutores y su relación con la participación de las familias. Revista del Consejo Escolar del Estado, 4(7), 29-37. Recuperado de:https://sede.educacion.gob.es/ publiventa/descarga.action?f codigo agc $=17382$

Colás, P. S., \& Contreras, J. A. (2013). La participación de las familias en los centros de educación primaria. Revista de Investigación Educativa, 31(2), 485-499. Recuperado de: http:// revistas.um.es/rie/article/view/171031/15820 
García, C., Martín, N., \& Sampé, M. (2012). La implicación y la participación de las familias: elementos clave para la mejora del aprendizaje en los centros educativos con alumnado inmigrante. Indivisa: Boletín de estudios e investigación, (13), 192-212. Recuperado de: https://dialnet.unirioja.es/servlet/articulo?codigo $=4247344$

García, M. P., Gomariz, M. A., Hernández, M. A., \& Parra, J. (2010). La comunicación entre la familia y el centro educativo, desde la percepción de los padres y madres de los alumnos. Educatio siglo XXI, 28(1), 157-188. Recuperado de: http://revistas.um.es/educatio/ article/view/109771/104461

Garreta, J. (2015). La comunicación familia-escuela en Educación Infantil y Primaria. Revista de la Asociación de Sociología de la Educación, 8(1), 71-85. Recuperado de: https://ojs. uv.es/index.php/RASE/article/view/8762/8305

Gibbs, G. (2012). El análisis de datos cualitativos en investigación educativa. Madrid: Morata.

Gil, F. (1994). Investigando las relaciones familia-escuela. La participación de los padres en el centro. Revista de Pedagogía de la Universidad de Salamanca, (6), 67-76. Recuperado de: https://dialnet.unirioja.es/servlet/articulo?codigo=122490

Jiménez, L., Lorence, B., \& Menéndez, S. (2008). Familia y adaptación escolar durante la infancia. XXI. Revista de Educación, (10), 97-110. Recuperado de: https://docs.google.com/ viewerng/viewer?url=idus.us.es/xmlui/bitstream/handle/11441/30837/Familia+y+adap taci\%C3\%B3n+escolar+durante+la+infancia.pdf?sequence\%3D1\&isAllowed=y

Jurado, C. (2009). La familia y su participación en la comunidad educativa. Innovación y experiencias educativas, (23), 1-10. Recuperado de: https://archivos.csif.es/archivos/andalucia/ ensenanza/revistas/csicsif/revista/pdf/Numero 23/CARMEN JURADO GOMEZ01.pdf

Maese, A. B. (2009). Familia y escuela. Los pilares de la educación. Innovación y experiencias educativas, (14), 1-11. Recuperado de: https://archivos.csif.es/archivos/andalucia/ensenanza/revistas/csicsif/revista/pdf/Numero_14/ANA\%20BELEN_MAESTRE_1.pdf

Meneses, J., \& Rodríguez, D. (2011). El cuestionario y la entrevista. Barcelona: Universitat Oberta de Catalunya.

Muñoz, A. (2005). La familia como contexto de desarrollo infantil. Dimensiones de análisis relevantes para la intervención educativa y social. Portularia, 5(2), 147-163. Recuperado de: http://rabida.uhu.es/dspace/bitstream/handle/10272/505/b1518923.pdf?sequence=1 
San Fabián, J. L. (1996). El centro escolar y la comunidad educativa: ¿Un juego de metáforas? Revista de educación, (309), 195-215. Recuperado de: https://www.mecd.gob.es/dctm/revista-de-educacion/articulosre309/re3090800456.pdf?documentId=0901e72b81272f28

Valdivia, C. (2008). La familia: concepto, cambios y nuevos modelos. La Revue du REDIF, 1, 15-22. Recuperado de: http://moodle2.unid.edu.mx/dts cursos mdl/lic/DE/PF/AM/05/ cambios.pdf 